\title{
Phonetic Matching, Semanticized Phonetic Matching and Phono-Semantic Matching as Techniques in Keyword Selection
}

\author{
Yan Chen ${ }^{1}$ \\ ${ }^{1}$ Department of English Education, School of Foreign Languages, Yancheng Teachers University, Yancheng, \\ Jiangsu, China \\ Correspondence: Yan Chen, Department of English Education, School of Foreign Languages, Yancheng \\ Teachers University, Yancheng, Jiangsu, China. E-mail: cyan@xmu.edu.cn
}

$\begin{array}{lc}\text { Received: January 8, } 2017 & \text { Accepted: January 30, } 2017 \quad \text { Online Published: February 8, } 2017 \\ \text { doi:10.5539/ells.v7n1p45 } & \text { URL: http://dx.doi.org/10.5539/ells.v7n1p45 }\end{array}$

\begin{abstract}
In foreign language vocabulary learning, the keyword method is among the most widely researched mnemonics and has been proved effective by numerous empirical studies. To use the keyword method, a keyword in the native language must be selected for the creation of an image or a sentence of the keyword "interacting" with the target word in the foreign language, thus facilitating retention and retrieval of the target word. In an attempt to contribute to successful application of the keyword method, this paper outlines three techniques in keyword selection, i.e., phonetic matching, semanticized phonetic matching, and phono-semantic matching, by mainly drawing on example pairs from Chinese and English. The phonetic and semantic links between keyword and target word pairs derived through each technique are analysed, and possible pitfalls are addressed as well.
\end{abstract}

Keywords: target word, keyword, phonetic matching, semanticized phonetic matching, phono-semantic matching

\section{Introduction}

The learning of vocabulary is a fundamental task in language learning. In order to build up word power, learners of a foreign language often adopt various vocabulary learning strategies and researchers conduct in-depth researches into those strategies (e.g., Nation, 1990). Some researchers (e.g., O'Malley, Chamot, Stewner-Manzanares, Kupper, \& Russo, 1985; Zhang \& Gao, 2004) have found that strategies that entail less active manipulation of the task, e.g., rote repetition, were more frequently employed than those that entail active manipulation of learning materials, e.g., keyword techniques, by some learner groups. Among the latter kind of strategies is the keyword method which was initially developed by Atkinson (1975). A substantial number of empirical studies have investigated the effects of the keyword method in foreign language vocabulary learning, with an overwhelming majority of research findings proving the effectiveness of the method and only a few proving uncertain or poor effects for long-term retention (e.g., Wang, Thomas \& Ouellette, 1992; cf. Ellis \& Beaton, 1993). (Note 1) Among the researchers of the keyword method, some (e.g., Pressley, Levin, \& Delaney, 1982, p. 84) have pointed out in passing that it is a challenging task to prepare materials for keyword studies as the method can be applied only to items for which acoustically similar words can be generated. Esposito (2016, p. 107) mentions that "[f]inding phonetic similarity between English and Japanese words is not always easy and in some cases impossible". Similarly, Bird \& Jacobs (1999) point out that the difficulty encountered in finding phonetic links between Chinese and English limits the potential of the keyword method for Chinese students learning English. To the extent that the keyword method is generally effective in vocabulary learning, the difficulty in implementing the method deserves further exploration. Regretfully, the issue of how to derive keywords is hardly delved into in the literature about the keyword method so far.

In view of the importance of learning new vocabulary in foreign language acquisition as well as the lack of literature on how to derive a keyword for application of the keyword method, we will attempt to address the issue of how to form a keyword for the application of the keyword method in learning foreign language vocabulary. We will begin with a brief introduction to the keyword method, and delineate three techniques (Note 2) in deriving keywords, i.e., phonetic matching ("PM"), semanticized phonetic matching ("SPM") and phono-semantic matching ("PSM"). These techniques are identified through comparison of the pronunciation and meaning of a keyword and those of a word to be learnt (i.e., target word). As the terms PM, SPM and PSM 
have been elaborated on by Zuckermann $(1999$, p. 331, 2003, 2004, 2009) in the context of neologization, we will point out the differences in purpose and function when the techniques are used in different contexts. Due to the limit of our language proficiency, most of the keyword and target word pairs will be Chinese-English pairs. The questions to be answered include the following:

1) What types of keywords are likely to be derived through PM?

2) How is the semantic link between the keyword and the target word established through SPM and PSM?

3) In what ways is the use of the three techniques in the keyword method situation different from their use in the context of neologization?

It should be noted that where the Chinese language is involved, the keyword may be a one-character word, e.g., 嚎 (háo, literally "howl") for the target word howl, or a multi-character expression that is a phrase, e.g., 挖雷 (wā léi, literally "dig + landmine") for the target word worry, or a clause, e.g., 胎若爆 (tâi ruò bào, literally "tyre + if + have a puncture") for the target word terrible, or a sentence, e.g., 太母婆落泪 (tàimǔpó luòlèi, literally "grandma + shed tears") for the target word temporary. It is hoped that our delineation will provide useful insights into the techniques of selecting keywords and contribute to the use of the keyword method in foreign language vocabulary learning.

\section{A Brief Introduction to the Keyword Method}

Mnemonics refer to learning techniques that aid information retention in the human memory. Ever since antiquity, mnemonics as memory aids have drawn the attention of philosophers, educators, psychologists, language practitioners, teachers and students, etc. As the memorization of foreign language vocabulary has remained a primary task for learners of that foreign language, mnemonics for memorizing new vocabulary items have been developed, experimented, and investigated extensively in the past and there has been a considerable amount of empirical researches into the effects of mnemonic methods in foreign language vocabulary learning (e.g., Atkinson 1975; Nation, 1982, 1990; Hulstijn, 1997; Worthen \& Hunt, 2011; Esposito, 2016). Among the most widely researched mnemonics is the keyword method, which was originally conceived by Atkinson (1975). To put it simply, the keyword method is a two-step procedure for learning foreign vocabulary items, specifically for remembering a new item that has an associative component. The first step is to link the target word to a native-language word or phrase that is phonetically similar to part or all of the target item (to forge an acoustic link). The second step is to create an image of the keyword "interacting" with the target word (to establish an imagery link). For example, to learn the German word $E i$ (i.e., egg), English learners may use the English word eye as a keyword, and then visualize an image of an eye inside an egg, which may help them remember and retrieve the word Ei. Similarly, to memorize (la) voiture, the French word for English car, English learners may think of an English word to represent the sound of the French word, for instance, vulture (a type of carrion bird) which is phonetically close, and then forge a mental image for a car which will be associated with a vulture. They may imagine a woman driving a pink car with a vulture as a hood ornament or sitting in a back seat, in which case the sound of the keyword vulture serves as a phonetic clue to voiture and the image of a woman as a grammatical clue to the gender of voiture: a feminine noun preceded by the article la. In both cases, a phonetic and image linkage between the target word and the keyword in the native language is created.

In reality, the keyword method may be applied with some variation. For example, a verbal version of it is different from the imagery version in that at the last stage, a sentence is made up in the native language that involves both the keyword and the target word. An example from Pressley et al. (1982, p. 62) may suffice to illustrate this. Learners may use the English word cart as a keyword for Spanish carta. For a meaningful interaction involving the keyword (i.e., cart) and the target word's definition (i.e., postal letter), in contrast to generating an interactive visual image of a postal letter inside a shopping cart, learners can create a meaningful sentence to link the keyword cart to the target word's definition, as in "The cart transported the letter".

All in all, in the keyword method, it is hoped that the target word as a stimulus would trigger the activation of a phonetically similar keyword in the native language, which would in turn activate an interactive image or a sentence involving both the pronunciation and the meaning of the target word, thus leading to retention and retrieval of the target word.

\section{Selecting Keywords through Phonetic Matching, Semanticized Phonetic Matching, and Phono-Semantic Matching}

\subsection{Phonetic Matching in Keyword Selection}

Phonetic matching is a technique by which a native-language word which is phonetically similar to the target word is chosen as the keyword. In a keyword situation, once the learner encounters a target word, s/he needs to 
search in the native language for words that sound like the target word. In other words, the first criterion for the selection of a keyword is phonetic similarity to the target word, as in the case of English cart for Spanish carta, or English vulture for French (la) voiture. Phonetic similarity between the paired words may be partial or inaccurate, as the keyword may conform to only some of the phonetic patterns of the target word. Take for example the pairs 卡壳 (kă ké, literally “stuck”) vs. cacophony and 撕纸 (sī zhǐ, literally “tear up + paper”) vs. schism, the former of which merely imitate part of the pronunciation of the latter. When the method is used in two languages with distinct phonological systems, phonetic similarity can hardly be perfect, no matter how close a pair may sound. In pairs like 死壮 (sǐ zhuàng, literally “very, really + strong”) vs. strong, 死叮 (sǐ dīng, literally “fixedly + sting") vs. sting, 叶漏 (yè lòu, literally “leaves + leak") vs. yellow, the two words have a high degree of phonetic resemblance, but as Chinese is a tonal language while English is not, they cannot sound exactly like each other in natural speech.

In some language pairs, there exist words similar in pronunciation and even in orthography, as in the case of false friends, like German Handy (i.e., mobile phone) vs. English handy, Spanish embarazada (i.e., pregnant) vs. English embarrassed, French sensible (i.e., sensitive) vs. English sensible, but the selection of a keyword is not effortless since the number of false friends between languages is relatively small. To derive a keyword, learners need to use the pronunciation of the target word as a starting point. More often than not, a keyword's acoustic fidelity to the target word is distorted in one way or another. Addition or deletion of syllables, substitution of a syllable in the target word with a different one in the native language, etc. are prevalent in the chosen keywords, as in pairs like 咯咯 (gēgē, literally "giggle") vs. giggle, 嚎若爆 (háo ruò bào, literally "howl + as if + explode") vs. horrible, 何处受他 (héchù mì tā, literally “where + look for + him”) vs. hermit, 我不听你的 (wǒ bú tīng nǐde, literally "I + not + listen to + you") vs. obstinate.

Even if a similar-sounding keyword is selected, the word itself may have nothing to do with the true meaning of the target word. For instance, 我拆屋 (wǒ chāi wū, literally "I + demolish + house") is not semantically related to English achieve, but may trigger an interactive image in which a person assigned the task of demolishing a house has finished his job, thus functioning as a feasible link to facilitate retention and retrieval of the word achieve. In a similar manner, 额必死 (é bì sǐ, literally "I + definitely + die") is a good keyword for abyss as a person trapped in an abyss is likely to predict his destiny in this way. In these cases, semantic irrelevance poses no obstacle as long as association can be established between the word pairs.

A pitfall in phonetic matching may arise if a keyword is formed by simply assembling Chinese words sounding similar to the target word, for the result might be a nounce or nonsense word which cannot trigger any association with the target word. A case in point is Chinese 袋呢梢 (dài ne shāo, literally "bag, pocket + particle + tip, the thin end of a twig, etc.") which matches English dinosaur phonetically but offers no room for association with the latter, for 袋呢梢 is not a meaningful combination in Chinese. In this case, phonetic matching is employed in the same way as notating the pronunciations of foreign words with similar-sounding Chinese words, so much so that the word thus derived functions as a phonetic transcription rather than as a keyword. Therefore, a word resulted from phonetic matching may or may not qualify as a keyword when Chinese is involved, and it does not matter if the semantic association between a keyword and a target word is right or not; what really matters is if the association contributes to memorizing and retrieving the target word when the need arises.

Though phonetic similarity is a must in keyword selection, the chosen word itself must be meaningful to trigger an image or verbal context in the mind of the learner for him or her to connect to the meaning of the target word. The meaningfulness of the keyword itself is important, otherwise it cannot serve as a mnemonic link to element(s) that will help in recall of the target word. Ample evidence has demonstrated that for the keyword to work, it must contain a link to sound, meaning, sound and meaning together, structure, context, mental image, letter(s) in the target word, etc. (see e.g., Cohen \& Aphek, 1980). To select a keyword that meets the phonetic requirement and is meaningful per se, we must choose and discard repeatedly until we form a satisfactory keyword.

\subsection{Semanticized Phonetic Matching in Keyword Selection}

By semanticized phonetic matching, a keyword is chosen that is similar to the target word phonetically, as well as semantically but in a loose way. Although we cannot measure how semantically close they are, we may recognize how they are related in meaning.

\subsubsection{Referent-SPM in Keyword Selection}

In some cases, the keyword is semantically related to the referent of the target word, hence the term referent-SPM. For example, in the keyword 爱你猫 (ài nĭ māo, literally “love + you/your + cat"), the component 
猫 (māo, literally “cat”) belongs to the category of the target word animal; the component 四拐 (sì guăi, litrally "four + angle") in the keyword 四拐哦 (sì guăi ò, literally "four + angle + particle") is linked to the target word square which refers to a flat shape with four equal sides and right angles. Similarly, the component 他 (tāa, literally "him") in the keyword 何处受他 (héchù mì tā, literally “where + look for + him") is related to the referent of the target word hermit and reminds the learner that a hermit is a human being; the component 钱袋子 (qián dàiž̀, literally “money + bag”) in the keyword 摸钱袋子 (mō qiándàiž́, literally “touch + money bag”) is related to the target word merchandise, for the buying and selling of manufactured goods cannot be carried out without involving a wallet or purse or bag or anything that is used for keeping money in. The component 乳 (rŭ, literally "breast") in the keyword 扛个乳 (káng gè rŭ, literally "carry + quantifier + breast") is related to the referent of the target word kangaroo as breasts and pouches are biological traits of female kangaroos.

\subsubsection{Sense-SPM in Keyword Selection}

In other cases, the keyword is semantically related to the sense of the target word rather than to the referent, hence the term sense-SPM. For example, the keyword 散的 (sànde, literally "loose") explains a feature of the target word sand, which is familiar to native Chinese speakers as in the idiom 一盘散沙 (yīpán sàn shā, literally "a plate + loose + sand"). The keyword 懒散态度 (lănsàn tàidù, literally "sluggish + attitude") and the target word lassitude have something in common semantically, for a person with a 懒散态度 usually shows a lack of physical or mental energy. The meaning of the keyword 我怕 (wǒ pà, literally "I + fear") and that of the target word appall are in a result-cause relation. The keyword 浮老哥 (fú lăogē, literally "floating + elder brother") indicates a feature of the target word frog with the component 浮 (fú, literally "floating"). The meaning of the keyword 背噢 (bèi $\overline{0}$, literally "unlucky + particle") can be applied to creatures suffering from a bale. The keyword 结巴 (jiébā, literally "stammer, stutter") and the target word jabber share the meaning "talk or speak in a way that is hard to understand". 凌迟 (língchí, literally "put to death by dismembering the body") is related to lynch as both are ways of putting people to death. 楷模 (kăimó, literally "model, good example") as a keyword for camel is a good choice as the camel is often regarded as a model for endurance in hard work and devotion. 不一样的 (bú yīyàngde, literally "not + the same") entails a feature of either surpassing or lagging behind, the former of which is implied in beyond.

\subsection{Phono-Semantic Matching in Keyword Selection}

By phono-semantic matching, a keyword is chosen that is similar to the target word both phonetically and semantically. Our intuition may tell us that such word pairs are rare in any pair of language, but we do have some examples. The keyword 飞离 (fêilí, literally "quickly + leave") is a vivid description of the target word flee; a person who is 胖得要死 (pàng dé yàošr, literally “fat + particle + extremely") is usually ponderous, so these two match each other both phonetically and semantically. 太热的 (tài rè de, literally "too + hot") sounds highly similar to torrid and means the same as the latter. 死叮 (sî dīng, literally “fixedly + sting") is a good keyword for sting, although the former is more emphatic than the latter; the same is true with 死壮 (sĩ zhuàng, literally "very, really + strong") as a keyword for strong.

Unlike keywords derived by means of PM, those resulted from SPM and PSM are semantically related to the target words in one way or another, which does not mean that they may function as better keywords than the former kind. As is shown in the above discussion of PM, to the extent that a keyword contributes to retention and retrieval of the target word, it is a good keyword.

\section{Phonetic Matching, Semanticized Phonetic Matching, and Phono-Semantic Matching in Keyword Selection versus in Neologization}

The terms PM, SPM and PSM were originally employed to designate camouflaged borrowing in the context of neologization by Zuckermann $(1999,2003,2004,2009)$; they respectively refer to the use of pre-existent target language (in this context, native language) roots/lexemes as the basic material for the neologization where the target language material is originally similar to the source language (in this context, foreign language) lexical item only phonetically, phonetically and semantically but in a loose way, and both phonetically and semantically. Zuckermann (ibid.) has made it clear that they are important phenomena in neologization and prevalent in two major language groups: (1) languages using phono-logographic scripts like Chinese and Japanese (only when kanji are used), and (2) reclaimed languages like Israeli Hebrew, revolutionized languages like Republican Turkish, and puristically-oriented languages like Icelandic (Sapir \& Zuckermann, 2008), where language planners endeavour to replace undesirable foreign elements with native language material. Subsequent researches into these techniques have revealed their role in translation and their marketing potential in contemporary China (e.g., Fleming \& Zuckermann, 2013; Hu, 2016).

However, in contrast to PM, SPM and PSM as means of neologization, the purpose of which is to create a word 
to fill a lexical void or to replace an unwelcome one in the native language, PM, SPM and PSM in foreign language vocabulary learning are employed as techniques to establish phonetic as well as semantic links between a target word and a native expression with the ultimate aim of facilitating memory of the target word. For instance, the keyword 额的妈呀 (éde mā ya, literally "my + Mom + particle", i.e., an exclamation of surprise similar to "Oh, my God!") for English admire may imply the reaction or attitude of the speaker when s/he encounters something that is usually regarded with wonder, pleasure, or approval, for instance, an idol of some kind or other. In a keyword situation, 额的妈呀 is not a translational equivalent of admire, nor is it a word newly coined so as to adopt admire into Chinese, but a phonetic and semantic cue for learners to learn the word admire. The keyword 拍死它 (pāi sǐ tā, literally “pat, beat + die + it", i.e., beat it until it dies) for English pest shows the instinctive reaction of people on seeing a pest, but it is not used as an equivalent of pest in vocabulary learning process. In both cases, since the target words have ready equivalents in Chinese, the keywords function merely as a bridge for learners to go from the phonetic form of the target word to a Chinese expression which in turn may serve as a clue for learners to approach the target word both phonetically and semantically.

In order for associated pairs to work well, the person who tries to create associations has to take into consideration both pronunciation and associative potential simultaneously. In language learning contexts where Chinese is involved, it should be noted that unlike a neologism which should have the potential to function as a normal word in communication, the keyword is nothing but a transitional expression expected to help memorize (and retrieve) the target word. As learners have come to a good mastery of the target word, they may as well abandon the keyword.

\section{Conclusion}

In the above discussion, we have presented three techniques in keyword selection through analysis of example pairs. To learners of a foreign language, especially those at the initial learning stage, foreign vocabulary items are mostly opaque, which means they can hardly see any connection between those words and words they already know of their native language. Therefore, the search for mnemonic methods and relevant techniques in foreign language vocabulary learning is a never-ending process, for learners have to commit a massive number of new words to memory. To facilitate memorization of target words, learners have to try various mnemonics to establish a link to a target word that is difficult to remember. As the link connects the two items in their memory, retention of one of them will help retention of the other. Phonetic matching, semantcized phonetic matching and phono-semantic matching may help learners relate target words to what they already know, form mental images, and create associations among information that needs to be remembered. However, learner factors like age, gender, motivation, language aptitude, prior knowledge, personality, learning habits and preferences, etc. may influence the use of these techniques. This paper is but an initial and limited effort at outlining the techniques, and empirical studies remain to be made to examine the efficacy of these techniques. We believe that with a basic understanding of how to use the techniques to derive keywords and through constant rehearsal, learners may grow in their ability to deal with vocabulary memorization tasks.

\section{Acknowledgements}

A research project supported by Yancheng Teachers University under Grant 12YSYJB0105, and by Education Department of Jiangsu Province and Finance Department of Jiangsu Province under Grant Top-notch Academic Programs Project of Jiangsu Higher Education Institutions.

\section{References}

Atkinson, R. C. (1975). Mnemotechnics in second-language learning. American Psychologist, 30, 821-828. http://dx.doi.org/10.1037/h0077029

Bird, S. A., \& Jacobs, G. M. (1999). An examination of the keyword method: how effective is it for native speakers of Chinese learning English? Asian Journal of English Language Teaching, 9, 75-97.

Cohen, A., \& Aphek, E. (1980). Retention of second-language vocabulary over time: Investigating the role of mnemonic associations. System, 8, 221-235. https://doi.org/10.1016/0346-251X(80)90004-4

Ellis, N., \& Beaton, A. (1993). Factors affecting the learning of foreign language vocabulary: Imagery keyword mediators and phonological short-term memory. The Quarterly Journal of Experimental Psychology, 46A(3), 533-558. https://doi.org/10.1080/14640749308401062

English Oxford Living Dictionaries (2017). Retrieved from https://en.oxforddictionaries.com/

Esposito, J. (2016). Mnemonics as a cognitive-linguistic network of meaningful relationships. The Journal of Language Teaching and Learning, 6(1), 105-113. 
Fleming, S., \& Zuckermann, G. (2013). One name, two parents: The marketing potential of phono-semantic matching in China. In O. Felecan (Ed.), Proceedings of ICONN 2 (pp. 119-138). Baia Mare, Romania.

$\mathrm{Hu}$, J. C. (2016). The genius and stupidity of corporate America are on display when companies rebrand for new countries. Retrieved from https://qz.com/816544/phono-semantic-matching-corporate-branding/

Hulstijn, J. H. (1997). Mnemonic methods in foreign language vocabulary learning. In J. Coady \& T. Huckin (Eds.), Second Language Vocabulary Acquisition (pp. 203-224). Cambridge: Cambridge University Press.

Nation, I. S. P. (1982). Beginning to learn foreign vocabulary: A review of the research. RELC Journal, 13, 14-36. https://doi.org/10.1177/003368828201300102

Nation, I. S. P. (1990). Teaching and Learning Vocabulary. Boston, Mass.: Heinle \& Heinle Publishers. http://dx.doi.org/10.1016/0346-251X(94)90065-5

O’Malley, J. M., Chamot, A. U., Stewner-Manzanares, G., Kupper, L., \& Russo, R. P. (1985). Learning strategies used by beginning and intermediate ESL adult students. Language Learning, 35(1), 21-46. https://doi.org/10.1111/j.1467-1770.1985.tb01013.x

Pressley, M., Levin, J. R., \& Delaney, H. D. (1982). The mnemonic keyword method. Review of Educational Research, 52(1), 61-91. http://dx.doi.org/10.3102/00346543052001061

Sapir, Y., \& Zuckermann, G. (2008). Icelandic: Phonosemantic matching. In J. Rosenhouse \& R. Kowner (Eds.), Globally Speaking: Motives for Adopting English Vocabulary in Other Languages (pp. 19-43). Clevedon, Buffalo, Toronto: Multilingual Matters.

Taheri, A. A., \& Davoudi, M. (2016). The effect of the keyword method on vocabulary learning and long-term retention. International Journal of Language and Linguistics, 3(1), 114-125.

Wang, A. Y., Thomas, M. H., \& Ouellette, J. A. (1992). Keyword mnemonic and retention of second-language vocabulary words. Journal of Educational Psychology, 84(4), 520-528. http://dx.doi.org/10.1037/0022-0663.84.4.520

Worthen, J. B., \& Hunt, R. R. (2011). Mnemonology: Mnemonics for the 21st Century. New York: Psychology Press.

Zhang, W., \& Gao, Y. (2004). English vocabulary memorizing strategies by Chinese university students. Sino-US English Teaching, 1(6), 69-76.

Zuckermann, G. (1999). Review article of Nakdimon Shabbethay Doniach and Ahuvia Kahane (Eds.). The Oxford English-Hebrew Dictionary. Oxford-New York: Oxford University Press, 1998. International Journal of Lexicography, 12, 325-346.

Zuckermann, G. (2003). Language Contact and Lexical Enrichment in Israeli Hebrew. London, New York: Palgrave Macmillan. http://dx.doi.org/10.1057/9781403938695

Zuckermann, G. (2004). Cultural hybridity: Multisourced neologization in "reinvented" languages and in languages with "phono-Logographic" script. Languages in Contrast, 4(2), 281-318. https://doi.org/10.1075/lic.4.2.06zuc

Zuckermann, G. (2009). Hybridity versus revivability: Multiple causation, forms and patterns. Journal of Language Contact, VARIA 2, 40-67. https://doi.org/10.1163/000000009792497788

\section{Copyrights}

Copyright for this article is retained by the author(s), with first publication rights granted to the journal.

This is an open-access article distributed under the terms and conditions of the Creative Commons Attribution license (http://creativecommons.org/licenses/by/4.0/). 